\title{
ANALISIS PENGARUH HOLDING TIME TERHADAP SIFAT MEKANIS DAN STRUKTUR MIKRO PADA PROSES INDUCTION TEMPERING BATANG PISTON BAJA SCM $420 \mathrm{H}$
}

\author{
Budiarto dan Kimar Turnip \\ Program Studi Teknik Mesin, Fakultas Teknik, Universitas Kristen Indonesia \\ Jl. Mayjen Sutoyo no.2, Cawang, Jakarta \\ No.HP : 085719437651 \\ Email: budidamaz@gmail.com
}

\begin{abstract}
Selection of materials connecting rod for a component or structure usually involves several aspects, there are aspects of specific strength, stiffness, lightweight, noncorrosive materials and resistance or age. In the manufacturing process connecting rod always give heat treatment such as Normalizing, Carburizing, and Induction Tempering. In the process, Induction Tempering has a big problem in hardness after the process, not stable and liable to over from standard. Process condition of tempering induction temperature in 650 700 C at 1 atm pressure, \& holding time variation at 5 , 10, 15, and 20 seconds. Kind of tests such as bending test, magna-flux, hardness, and structure micro. Bending test report fiber flow is straight, not broke because not found micro crack portension at body connecting rod. Hardness test result min point 23 HRC and max point 39,2 HRC base on standard range 25 44 HRC. The results of surface morphological observation show that the martensite phase causes hardness value to increase.
\end{abstract}

Keywords : SCM $420 \mathrm{H}$ steels, piston rod, induction tempering, microstructure.

\section{PENDAHULUAN}

Kemajuan teknologi sekarang ini telah menghasilkan berbagai kreasi dalam segala hal yang bertujuan memudahkan segala aktifitas manusia. Ada berbagai sarana transportasi tersedia, mulai dari darat, udara, dan laut. Kendaraan yang diproduksi massal di negara kita umumnya kendaraan darat, salah satunya sepeda motor, dimana produksi sepeda motor roda dua sebanyak 6 juta buah per tahun. Diharapkan setiap sepeda motor memiliki umur yang lebih panjang maka selain komponen sepeda motor didesain dengan efektif dan efisien, juga tergantung dari material dari komponen tersebut. Salah satu contoh komponen sepeda motor ini yaitu Batang piston. Batang piston merupakan komponen penting pada sepeda motor, karena fungsinya adalah untuk meneruskan daya yang dihasilkan pada proses pembakaran dari torak menuju poros engkol pada motor.

Didalam proses manufacturing, conecting rod melalui beberapa tahapan salah satunya heat threathment yang bertujuan untuk mendapatkan sifat-sifat mekanik dan karakteristik material seperti tahan gesek, tahan aus, tahan panas, dst. Proses heat threatment tersebut antara lain : Normalizing, Carburizing, dan Induction Tempering. Proses Induction Tempering menjadi poin terpenting karena merupakan proses terakhir atau penentu keberhasilan dari conecting rod dari segi material. Jadi untuk mendapatkan dan menjaga kualitas produk dari sisi material sesui standar drawing, perlu dilakukan analisis terkait pengaruh paling penting didalam proses Induction Tempering yaitu holding time. Material conecting rod menggunakan baja paduan SCM $420 \mathrm{H}$, yang mana baja jenis ini karakteristik / sifatnya: keras, ulet, kemampuan tahan korosi yang tinggi serta memiliki kemampuan untuk dikeraskan. Karena baja SCM $420 \mathrm{H}$ memiliki kemampuan untuk dikeraskan maka baja jenis ini sering diaplikasikan untuk pembuatan produk dengan proses heat threatment, yang nantinya didapatkan produk yang memiliki sifat mekanis keras dipermukaan (tangguh, tahan gesek, tahan aus) namun lunak 
(ulet/tidak mudah patah) didalamnya. Nurkhozin (2006) telah melakukan penelitian tentang pengaruh proses flame hardening (salah satu jenis surface threatment) pada baja tempa SCM $420 \mathrm{H}[4]$. Danang (2009) melakukan penelitian pengaruh kecepatan torch dan jenis nyala api terhadap kekerasan permukaan baja karbon pada proses automatic flame surface hardening[4].

\section{METODOLOGI PENELITIAN}

Bahan: Spesifikasi benda uji yang digunakan dalam eksperimen ini adalah sebuah engine part yaitu conecting rod dimana benda tersebut terbuat dari baja SCM $420 \mathrm{H}$ yang telah mengalami pembentukan melalui proses tempa (forging), machining, dan surface threatment carburizing. Adapun data komposisi kimia (chemical composition) baja SCM $420 \mathrm{H}$ adalah sebagai berikut[3] :

Tabel 1. Komposisi unsur kimia Baja SCM 420 $\mathrm{H}$

\begin{tabular}{|c|c|c|}
\hline \multicolumn{3}{|c|}{ Komposisi unsur kimia (\%) } \\
\hline $\mathbf{C}$ & $\mathbf{S i}$ & $\mathbf{M n}$ \\
\hline $0,18-0,3$ & $0,15-0,4$ & $0,6-0,8$ \\
\hline $\mathbf{C r}$ & Mo & Fe \\
\hline $0,9-1,2$ & $0,15-0,3$ & sisa \\
\hline
\end{tabular}

\section{Cara kerja}

Mekanisme proses dari induction tempering adalah batang piston dipasang pada jig conveyor kemudian batang piston berjalan maju melewati coil yang didalamnya terdapat susunan pipa yang dialiri arus. Kemudian timbulah induksi dimana batang piston yang terbuat dari steel menjadi panas (panas yang timbul didapat dari proses induksi yaitu perubahan flux magnetic yang dilingkupi oleh loop kawat (coil) yang dialiri arus listrik) sampai temperatur yang ditentukan untuk fase tempering[1]. Setelah itu batang piston keluar dari coil dan melewati fase pendinginan udara terbuka. Setelah itu batang piston diambil dan ditempatkan pada tempat yang ditentukan. Parameter mesin untuk proses induction tempering adalah power control, speed meter, water leve[6]. Ketiga parameter tersebut merupakan parameter kunci untuk proses induction tempering conecting rod, serta menjaga temperatur material tetap difase tempering yaitu $600^{\circ} \mathrm{C} 650^{\circ} \mathrm{C}[5]$. Pada dasarnya proses induction tempering adalah untuk menurunkan kekerasan / melunakkan logam (baja) khususnya untuk melunakan batang piston, sehingga meningkatkan keuletan dan memenuhi standar kekerasan batang piston sesuai drawing yaitu 25 44 HRC[2]. Adapun yang menjadi point pengecekanya.

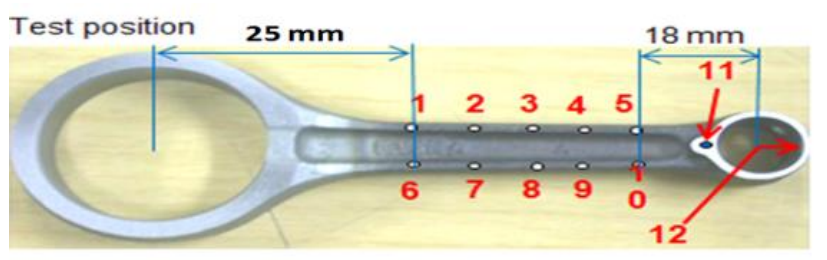

Gambar 1. Posisi uji kekerasan pada permukaan batang piston

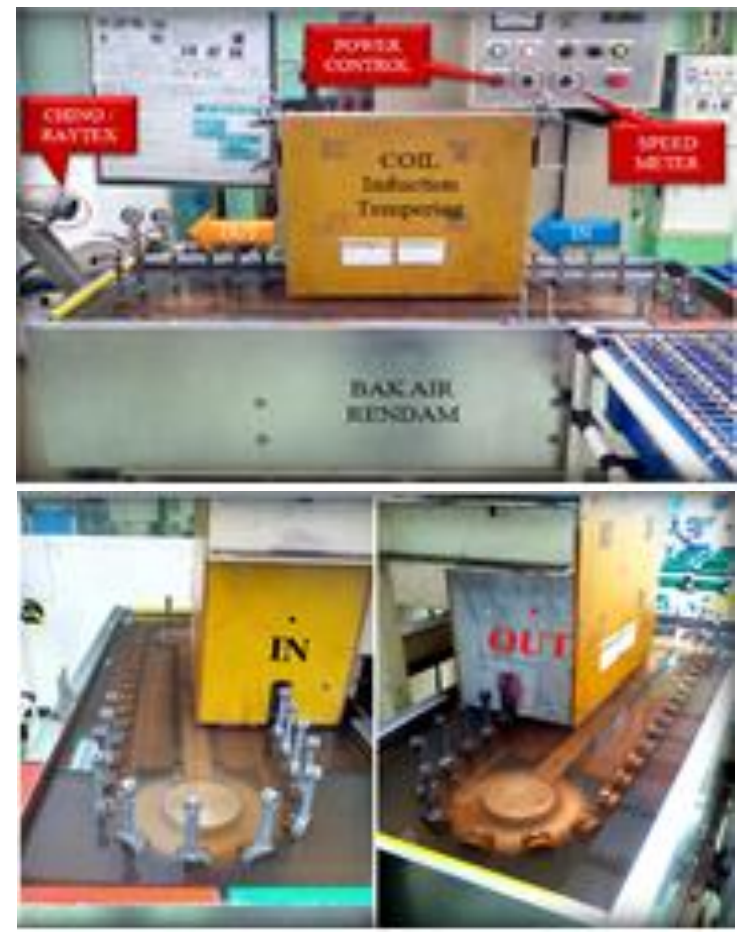

Gambar 2. Mekanisme Holding Time proses Induction Tempering 


\section{HASIL DAN PEMBAHASAN}

\section{a. Analisis hasil uji puntir}

Pengujian puntir ini bertujuan untuk mengetahui ketangguhan dan keuletan dari batang piston setelah proses induction tempering dari keseluruhan sampel material baja SCM $420 \mathrm{H}$. Hasil pengamatan pengujian puntir dimana secara visual dengan menggunakan alat Magnetic Particle Inspection atau proses magnaflux tidak ditemukan keretakan (crack). Bahkan ketika batang piston dibelah dengan wire cut dan dilakukan pengecekan fiber flow (batang piston dibelah, kemudian belahan tersebut direndam kedalam cairan asam klorida $(\mathrm{HCl})$ dengan temperatur dan waktu yang ditentukan) didapatkan serat material batang piston masih utuh / tidak terputus. Ini menandakan bahwa dari segi pengujian puntir batang piston yang diproses menggunakan mekanisme penahanan panas dengan cover penutup dari steel plate yang dilapisi glasswooll, cover penutup dari batu tahan api (refraktori) dan dengan mekanisme holding time hampir sama. Yang membedakan ketika pengujian batang piston yang diproses dengan mekanisme holding time cenderung lebih ulet atau liat. Sebagaimana diketahui dalam aplikasinya di mesin, batang piston khususnya dibagian batang mendapatkan panas dan gesekan yang tinggi yang ditimbulkan dari proses pembakaran motor[7].

Setelah batang piston dilakukan pengecekan Magnetic Particle Inspection (MPI) selanjutnya dilakukan pengujian fiber flow atau pengujian untuk melihat arah serat material batang piston. Fiber flow terlihat ketika produk dipotong / dibelah kemudian direbus kedalam cairan kimia khusus (cairan HCL) dengan temperatur tertentu dan waktu tertentu. Fiber flow merupakan poin terpenting dari pembentukan benda dari steel, apalagi pembentukannya dengan tempa (forging) dan yang telah mengalami perlakukan pengujian seperti tes puntir. Karena jika arah serat material terputus / tidak terbentuk maka kekerasan produk tidak merata dan berpotensi menjadi micro crack dan saat dilakukan assembling pada unit akan berpotensi retak bahkan bisa patah.

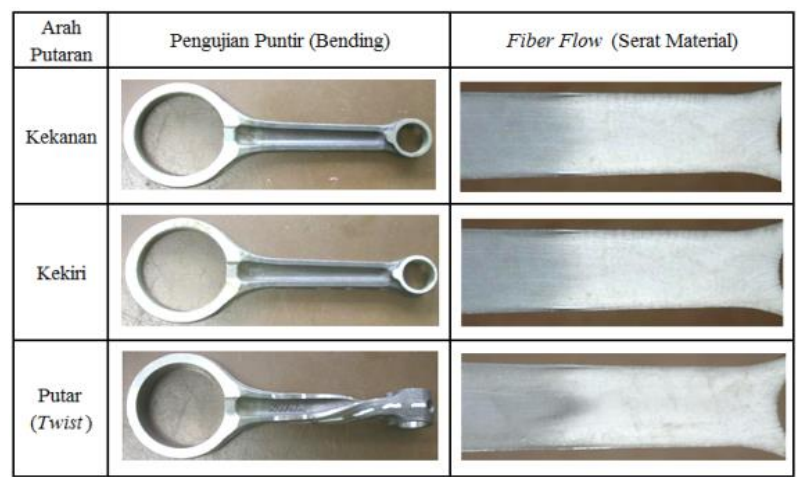

Gambar 3. Foto hasil pengujian puntir dan Fiber flow Batang piston

\section{b. Analisis induction tempering terhadap} holding time

Proses induction tempering dengan menggunakan mekanisme holding time ini dilakukan setelah melihat hasil pengujian kekerasan (hardness) dari percobaan sebelumnya yang masih over dari standar hardness di $25 \sim 44$ HRC. Setelah dianalisis potensi problem diakibatkan karena panas yang diterima oleh batang piston kurang merata. Jika mengunakan pengaturan power control max dan speed meter max diarea cek poin $2 \& 7$ selalu over sementara jika mengunakan pengaturan power control min dan speed meter min diarea cek poin $1 \& 6$ selalu over. Dari hasil analisis diatas agar panas yang diterima oleh batang piston merata maka mekanisme proses induction tempering dibuat stepping dengan memodifikasi speed conveyor stop \& run. Untuk proses ini dibutuhkan penambahan alat yaitu timer control yang dirangkai dengan sistem speed meter untuk mengatur kecepatan gerak dari conveyor. Sehingga ketika proses induction tempering berlangsung ada saat dimana batang piston yang terpasang pada jig conveyor berhenti dan berjalan (stop \& run). Panas pertama kali timbul dibagian tengah batang piston kemudian merambat kearah atas (menuju bagian Small-End Bore Diameter) dan kebawah (menuju bagian Big-End Bore Diameter), disaat panas muncul conveyor berhenti beberapa detik sehingga terjadi perambatan panas, kemudian jalan beberapa detik dan berhenti lagi maka terjadi perambatan panas kembali sampai batang piston 
keluar dari coil. Proses ini berjalan secara continue selama proses induction tempering berlangsung. Proses trial induction tempering dengan mekanisme holding time ini menggunakan parameter power control \& speed meter pada pengaturan middle kemudian mengkombinasikan kecepatan gerak conveyor berhenti dan berjalan (stop \& run).

Tabel 2. Data hasil uji kekerasan

\begin{tabular}{|c|c|c|c|c|c|c|c|c|c|c|c|}
\hline \multirow{2}{*}{ No Sample } & \multicolumn{10}{|c|}{ Point Check Hardness } \\
\cline { 2 - 12 } & 1 & 2 & 3 & 4 & 5 & 6 & 7 & 8 & 9 & 10 & 11 \\
\hline Sample 1 & 39.1 & 37.9 & 37.4 & 35.6 & 32.2 & 38.6 & 36.2 & 36.5 & 33.4 & 29.8 & 35.7 \\
\hline Sample 2 & 38.8 & 37.0 & 37.1 & 35.1 & 32.7 & 37.9 & 36.9 & 36.4 & 33.8 & 29.3 & 35.9 \\
\hline Sample 3 & 38.6 & 37.3 & 37.2 & 35.9 & 32.9 & 38.0 & 36.0 & 36.1 & 33.1 & 29.5 & 35.7 \\
\hline Sample 4 & 39.2 & 38.1 & 37.4 & 35.6 & 32.8 & 38.8 & 37.1 & 36.1 & 33.9 & 29.5 & 35.6 \\
\hline Sample 5 & 38.6 & 37.4 & 36.8 & 35.4 & 32.8 & 38.1 & 36.9 & 35.9 & 33.9 & 29.9 & 35.8 \\
\hline Sample 6 & 38.8 & 37.6 & 36.9 & 35.4 & 32.9 & 38.3 & 36.4 & 36.8 & 33.4 & 29.5 & 35.4 \\
\hline Sample 7 & 38.0 & 37.2 & 37.0 & 35.9 & 32.9 & 37.9 & 36.1 & 36.4 & 33.4 & 29.8 & 35.0 \\
\hline Sample 8 & 39.1 & 37.5 & 37.1 & 35.0 & 32.2 & 38.5 & 36.6 & 36.9 & 33.5 & 29.9 & 35.1 \\
\hline Hardness Max & 39.2 & 38.1 & 37.4 & 35.9 & 32.9 & 38.8 & 37.1 & 36.9 & 33.9 & 29.9 & 35.9 \\
\hline Hardness Min & 38.0 & 37.0 & 36.8 & 35.0 & 32.2 & 37.9 & 36.0 & 35.9 & 33.1 & 29.3 & 35.0 \\
\hline Ave & 38.7 & 37.5 & 37.1 & 35.5 & 32.7 & 38.3 & 36.5 & 36.4 & 33.5 & 29.6 & 35.5 \\
\hline
\end{tabular}

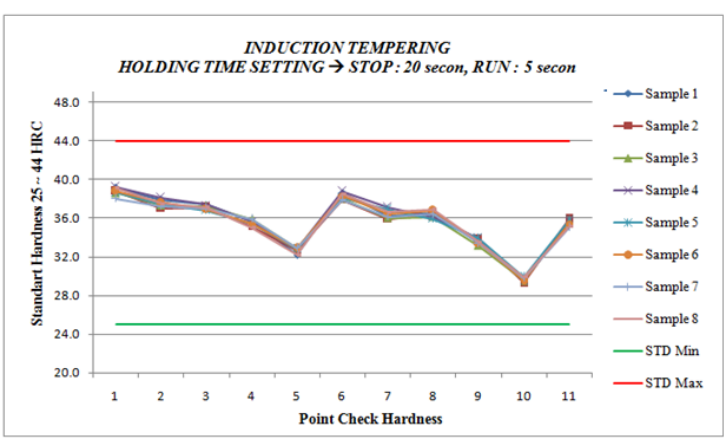

Gambar 4. Grafik Holding Time Setting Stop:

\section{c. Analisis struktur mikro} 20 Detik, Run: 5 detik

Pengujian struktur mikro dilakukan untuk mengetahui karakteristik batang piston dari struktur material. Setelah benda mendapatkan perlakuan panas induction tempering tentunya dari segi material pasti mengalami perubahan struktur.

Untuk itu dilakukan pengamatan morfologi permukaan atau struktur mikro yaitu pada hasil percobaan improvement atau pada percobaan keempat (proses induction tempering dengan menggunakan mekanisme holding time).

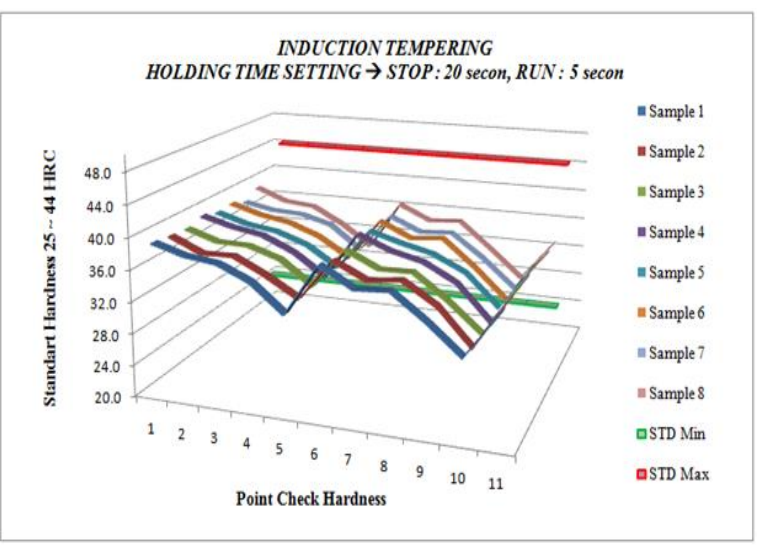

Gambar 5. Grafik Holding Time Setting Stop : 20 Detik, Run : 5, 10, 15, dan 20 detik

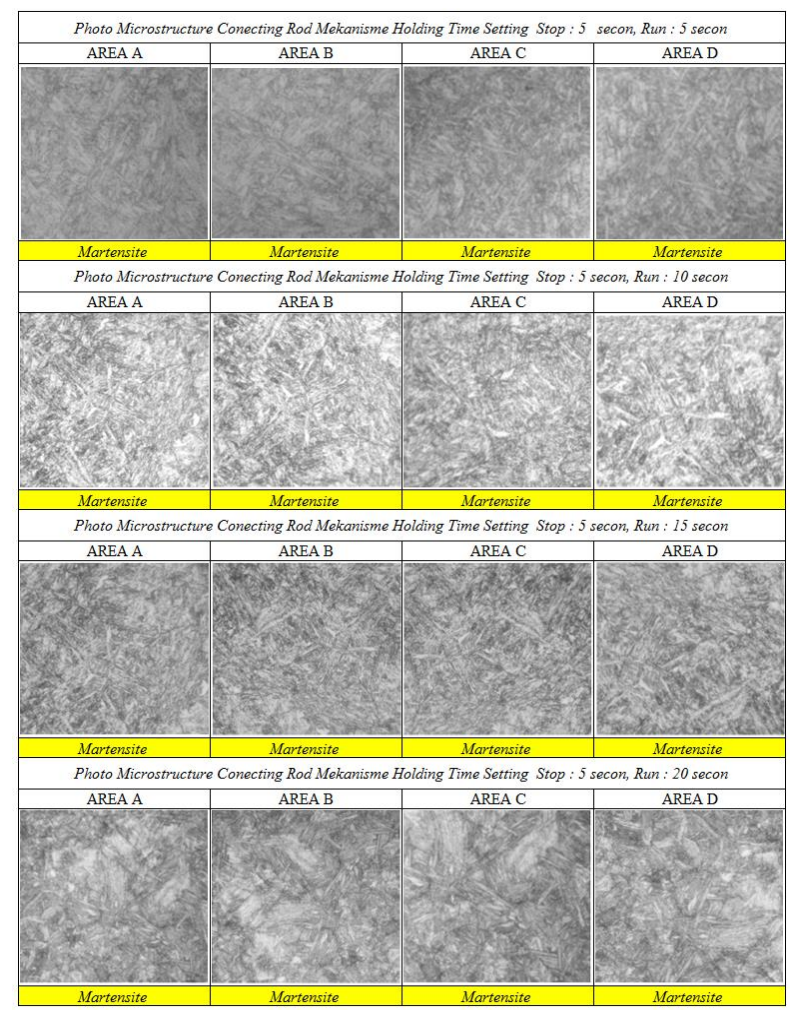

Gambar 6. Foto struktur mikro batang piston setelah heat treatment holding time, stop 5 detik, variasi run: $5,10,15$,dan 20 detik.

Prioritas pengujian hasil percobaan keempat ini dilakukan, karena nilai kekerasaannya telah memenuhi standar yang diijinkan, kemudian 
dilakukan pengujian yang lainnya. Setelah proses forging sampai dengan proses normalizing struktur material baja SCM $420 \mathrm{H}$ yang terbentuk adalah ferrite, bainite, dan perlite. Kemudian dilanjutkan proses carburizing hasilnya telah terbentuk fasa martensit, dimana karbon yang didifusikan ke batang piston dikedalaman 1,2 1,9 $\mathrm{mm}$ dengan nilai kekerasan $513 \mathrm{HVN}$. Hasil pengamatan morfologi permukaan setelah proses carburizing struktur mikronya telah berubah menjadi martensite, hal ini disebabkan pada dasarnya proses induction tempering ini hanya melunakan dan sekaligus menghilangkan tegangan sisa yang masih terdapat pada batang piston saat quenching (pendinginan cepat) pada proses carburizing berlangsung[8] Struktur mikro masih tetap didominasi oleh martensit dengan matrik ferrit. Hal tersebut terjadi dimungkinkan karena proses carburizing berlangsung jauh dibawah suhu kristalisasi martensit baja SCM 420.

\section{KESIMPULAN}

Dari hasil analisis dan improvement yang dilakukan dapat disimpulkan :

1. Waktu optimum untuk proses induction tempering batang piston dengan parameter setting: power control \& speed meter medium, conveyor speed adalah untuk stop: 20 detik dan run: 5 detik, menghasilkan nilai kekerasan yang paling terbaik.

2. Hasil pengamatan secara struktur mikro terbentuk fasa martensite

\section{DAFTAR PUSTAKA}

[1] Altan, T ,Gracious N and Shen G, (2005), Cold and Hot Forging Fundamentals and Application, ASM Internasional.

[2] Beumer, B.J.M. ; Anwir, B.S. (1978), IImu Bahan Logam, Jilid III,Cetakan ke-2, CV. Bhratara, Jakarta.

[3] Budinski K.G., Michael K. Budinski,(1999), Engineering Materials : Properties and selection, Prentice Hall, New Jersey.

[4] Danang, S.N., 2009, Pengaruh Kecepatan Torch dan Jenis Nyala Api terhadap Kekerasan Permukaan Baja karbon pada proses Automatic Flame Surface Hardening, Universitas Sebelas Maret.

[5] De Garmo, P., (196 9), Materials and Processes in Manufacturing, Mac Millan Company, New York.

[6] Nurkhozin, M., 2006, Pengaruh Manual Flame Hardening, Universitas Sebelas Maret.

[7] Smallman, R.E., J. Bishop, 1999, Metallurgi Fisik Modern dan Rekayasa Material, Jakarta : Erlangga.

[8] Wahid, Ir, Perlakuan Panas, 2001, Diktat ITS. 